\title{
Effect of vitamin B6 supplementation, in combination with magnesium, on severe stress and magnesium status: secondary analysis from an RCT
}

\author{
$\underline{\text { Lionel Noah }}^{1}$, Gisèle Pickering ${ }^{2}$, Claude Dubray ${ }^{2}$, Andre Mazur $^{3}$, Simon Hitier $^{1}$ and \\ Etienne Pouteau ${ }^{1}$ \\ ${ }^{1}$ Sanofi, Paris, France, \\ ${ }^{2}$ Clinical Pharmacology Department, CHU, Université Clermont Auvergne, Clermont-Ferrand, France and \\ ${ }^{3}$ Unité de Nutrition Humaine, INRA, Université Clermont Auvergne, Clermont-Ferrand, France
}

\section{Abstract}

Introduction: Evidence from a recent randomised controlled trial ${ }^{1}$ suggests that in severely stressed subjects with low magnesemia, supplementation with magnesium $(\mathrm{Mg})$ in combination with vitamin B6 (B6) provides greater benefits than $\mathrm{Mg}$ alone. B6 was reported to facilitate $\mathrm{Mg}$ absorption and its cellular uptake and to exert synergistic effect with $\mathrm{Mg}$. The current secondary analysis explored the relationship between $\mathrm{Mg}-\mathrm{B} 6$ combination and erythrocyte $\mathrm{Mg}$ concentration, used as a biomarker of body $\mathrm{Mg}$ status.

Material and Methods: An 8-week, Phase IV, controlled, single-blinded, parallel-group trial (EudraCT Number 2015-003749-24) stratified by sex was conducted in adults $(n=264)$ with a Depression Anxiety Stress Scales - stress subscale score (DASS-42SS) $>18$ and serum $\mathrm{Mg}$ of $0.5-0.85 \mathrm{mmol} / \mathrm{L}$, randomised $1: 1$ to daily oral $\mathrm{Mg}-\mathrm{B} 6$ (Magne $\mathrm{B} 6{ }^{\circledR}, \mathrm{Mg} 300 \mathrm{mg}$; B6 30mg) or oral Mg alone (Magnespasmyl $\left.{ }^{2}, \mathrm{Mg} 300 \mathrm{mg}\right)$. Outcomes were stress score, serum $\mathrm{Mg}(\mathrm{mmol} / \mathrm{L})$, erythrocytes $\mathrm{Mg}(\mathrm{mmol} / \mathrm{L})$, and serum B6 $(\mathrm{nmol} / \mathrm{L})$ from baseline to Week4 and Week8. Data are given as mean(SD) values.

Results \& Discussion: Baseline characteristics. Baseline magnesemia was 0.80(0.04) for both groups. Erythrocyte Mg concentration for the lower quintile of the studied population $(n=53)$ was $0.73-1.62$, below the normal range of $1.65-2.65$ in general population. The mean stress score in this subgroup was higher [29.5(6.3)], but not significantly different from that in other quintiles [lowest value: 26.1 (7.6)]. Baseline B6 serum level for the lower B6 quintile (5-23), below the normal range for general population, was suggestive of possible B6 deficiency.

Treatment effects. Both treatments increased slightly but not significantly erythrocyte $\mathrm{Mg}$ level from baseline to Week8 [1.84(0.03) to $1.86(0.03)$, and $1.86(0.03)$ to $188(0.03)$, respectively for $\mathrm{Mg}+\mathrm{B} 6$ and $\mathrm{Mg}$ groups]. Significant changes were observed in subjects with low erythrocyte $\mathrm{Mg}$ level at baseline (<1.6), namely an increase of $+0.13(0.04-0.22)$ for $\mathrm{Mg}+\mathrm{B} 6$ and $+0.17(0.08-0.25)$ for $\mathrm{Mg}$ groups, but with no difference between treatments. Moreover, $\mathrm{Mg}+\mathrm{B} 6$ supplementation led to a significant change $(\mathrm{p}<0.0001)$ in serum B6 level between baseline and Wk8 [55.9(4.8) to 370.9(11.3)], as compared to $\mathrm{Mg}$ alone [51.9(4.8) to 51.5(11.3)].

In conclusion, both treatments significantly increased erythrocyte $\mathrm{Mg}$ in subjects with low $\mathrm{Mg}$ status. B6 supplementation did not lead to further increase in erythrocyte $\mathrm{Mg}$ level. We have previously shown that severely stressed population benefits from B6 supplementation in combination with $\mathrm{Mg}$, however, the mechanism of the interaction between $\mathrm{Mg}$ and $\mathrm{B} 6$ remains to be elucidated.

${ }^{1}$ Sponsored by Sanofi

\section{Conflict of Interest}

Lionel Noah and Etienne Pouteau belong to the medical department, at CHC sanofi company. 